\title{
The Effect of Summarizing and Presentation Strategies on Reading Comprehension of Iranian Intermediate EFL Learners
}

\author{
Hooshang Khoshsima \\ Faculty of Management and Humanities \\ Chabahar Maritime University, Chabahar, Iran \\ E-mail: khoshsima@cmu.ac.ir \\ Forouzan Rezaeian Tiyar (Corresponding author) \\ Faculty of Management and Humanities \\ Chabahar Maritime University, Chabahar, Iran \\ E-mail: f.rezaeiantiyar@yahoo.com
}

Received: 05-02-2014

doi:10.7575/aiac.ijalel.v.3n.4p.88
Accepted: 16-03-2014

Published: 01-07-2014

URL: http://dx.doi.org/10.7575/aiac.ijalel.v.3n.4p.88

\begin{abstract}
The present study aimed to find out the effect of summarizing and presentation strategies on Iranian intermediate EFL learners' reading comprehension. 61 students were selected and divided into two experimental and control groups. The homogeneity of their proficiency level was established using a TOEFL proficiency test. The experimental group used the two strategies three sessions each week for twenty weeks, while the control group was not trained on the strategies. After every two-week instruction, an immediate posttest was administered. At the end of the study, a posttest was administered to both groups. Paired-sample t-test and Independent sample t-test were used for analysis. The results of the study revealed that summarizing and presentation strategies had significant effect on promoting reading comprehension of intermediate EFL learners. It also indicated that the presentation strategy was significantly more effective on students' reading comprehension.
\end{abstract}

Keywords: reading strategy, summarizing, presentation, reading comprehension, EFL learners

\section{Introduction}

Within the communicative, interactive, and learner-centered framework of language teaching and learning, students need to learn four skills of listening, speaking, reading, and writing for their educational success. But of all the language skills, reading enjoys a special focus in many second or foreign language academic contexts. As Nunan (1999, p.256) writes: "We interpret what we read in terms of what we already know, and we integrate what we already know with the content of what we are reading". Thus - reading considered as an active comprehension process. Most contemporary discussions among researchers focus on the teaching of, and use of multiple reading strategies to achieve comprehension. The main focus of these studies is to determine how reading strategies result in effective reading and how teachers can teach, combine, and manage these strategies while reading. Reading comprehension considered as a complex cognitive process which varies in numerous ways depending on tasks, motivations, purposes, and language abilities text (Grabe \& Stoller, 2002). Comprehension involves constructing meaning that is reasonable by relating what we attend in the world around us to what we already know and what we have in our heads about all of this information until it is understood. Thus - the point is comprehension, the final goal of reading, is not done in a vacuum. According to Lems, Miller, and Soro (2010) reading comprehension varies according to different purposes for reading and the texts that are used. They argued that this fact is accomplished through the use of different strategies. The main purpose of all reading is generally to get new information and/or for pleasure.

The process of reading implies the use of various strategies. Reading strategies give both teachers and students a chance to evaluate the degree of students' comprehension achievements. A short list of examples of comprehension strategies are appraised by the report of National Reading Panel-(2000) which are as follows: summarizing, forming questions, answering questions and elaborative interrogations, activating prior knowledge, monitoring comprehension, use text structure awareness, using visual graphics and graphic organizers, and inferencing (Grabe, 2009). Reading strategy instruction studies show that in the 1980's strategy instruction teachers began with a focus on teaching individual strategies but soon decided to teach a collection of strategies. Students can switch reading strategies according to the type of use. Each reader has the opportunity to use an individual mix of processing strategies in relation to a particular text and topic. It is explored in some studies that the use of various strategies helps the students in their reading both in L1 and L2 (Carrell, 1991; Bossers, 1992; Placeholder1; Nambiar, 2009).

Statement of the problem: 
In spite of its importance, comprehension process has long been the ignored skill in language teaching and learning. This lack of good comprehension is accelerated by the core role of reading in comprehension. One solution to the problem of poor reading comprehension is the learning of reading strategies. To achieve comprehension in reading, a proficient reader should be able to successfully implement such practices as relating the text with his or her own background knowledge, summarizing information, drawing conclusions, posing questions at the text, and utilizing appropriate strategies. Use of reading comprehension strategies facilitates a successful reading process. Therefore, to alleviate students' difficulties in comprehension of passages and to increase their motivation, reading strategies need to be focused for successful reading process in language teaching and learning. Allotting a certain amount of time to reading may be highly effective in improving reading success. A plethora of studies have been done to alleviate students' reading comprehension difficulties. Although these studies have investigated the role of reading comprehension in both L1 and L2 language contexts, it seems still necessary to conduct research considering learners' required abilities, needs, and skills in reading comprehension and help them decrease their reading difficulties.

Using reading strategies as practices of enhancing students' reading comprehension and focusing on reading as a process give students the chance to continue to read and take into account their dilemmas. Reviewing the literature on reading comprehension strategy training, especially in Iranian context, and among all the possible choices the present study intended to explore the effect of two important reading strategies of summarizing and presentation on students' reading comprehension. When summarizing strategy developed by Brown, Campione, and Day (1981) is referred to as a summary strategy which is rule-based, that is, it has a set of rules which each student takes into account to generate a summary (Marzano, Pickering, \& Pollock, 2001). Furthermore, Presentation strategy is regarded as a lecture or telling strategy used during teaching and learning process. The teacher is in control of presenting the topic and guides the students through the lesson. The teacher focuses the students' attention on the key points of the topic. Attempts were also made to investigate which of these two strategies have more significant effect on students' reading comprehension. As part of this effort, the study attempted to answer the following questions:

1. Does summarizing strategy have a significant effect on reading comprehension ability of Iranian intermediate EFL learners?

2. Does presentation strategy have a significant effect on reading comprehension ability of Iranian intermediate EFL learners?

3. Do summarizing and presentation strategies significantly improve reading comprehension ability of Iranian intermediate EFL learners?

\section{Review of Literature}

\subsection{Reading Comprehension}

Reading passages are usually used in English classes as a way of developing reading comprehension and learning new language. Our understanding of what reading comprehension is has been considerably shaped by the observable developments that researchers have taught over the last six decades (Grabe, 2009). Reading comprehension is regarded as an important component of the reading process. In reading comprehension process readers should utilize various conscious and unconscious strategies to solve their problem in order to understand the written massages. Since reading is a sophisticated cognitive process, it seems important that students should be trained to take active control of their own comprehension. Alfassi (2004) states that students should understand the meaning of texts, evaluate the messages, remember the concepts and contents, and apply the new knowledge properly. In order to accomplish this, reading research has proven that readers require a number of flexible comprehension strategies that they utilize before, during, and after reading. -Reading comprehension has recently been viewed as an interactive process that involves characteristics of the readers, the texts, and the tasks. Consequently reading comprehension has changed from one in which the reading texts had been given priority to one where the dominance lies in the different interactive components among the readers, the texts, and the different levels of knowledge (Grabe, 2009).

\subsection{Reading Strategy Instruction}

Reading strategies can be defined as "plans for solving problems encountered in constructing meaning" (Duffy, 1993, p.231-247). Several studies which have been conducted on the importance of English reading instruction showed that readers who can use different strategies are facilitated in reading comprehension. Wright and Brown (2006) investigated the potential of reading strategy instruction on students' reading comprehension ability. They considered its potential in raising the students' awareness of reading strategies, in developing the range of strategies they applied, and in encouraging learners to control and reflect upon their reading. The findings have demonstrated that strategy instruction could encourage learners to reflect on their strategy use and seemed to enhance their confidence in their own reading skills and abilities. Reading strategy instruction studies are classified into two main categories. The first category considers the readers' strategy use and the second category explores the effectiveness of reading strategy instruction on the readers' reading performance. In a recent study-Salataci and Akyel (2002) investigated the reading strategies of Turkish EFL students in Turkish and English and the possible effects of reading strategies on reading in Turkish and English. The findings indicated that strategy instruction had a positive effect on both Turkish and English reading strategies and reading comprehension in English. As it is implied in their study strategies can be taught successfully to students in the classrooms via strategy training. Similarly, the findings of a research demonstrated that when students are taught in the use of reading strategies had considerably better reading comprehension results than those who were not taught (Houtveen \& Van de Grift, 2007). 
Regarding the second category of the studies, Lee (2007) examined the effect of reading strategy instruction on reading comprehension and strategy use of Korean university students. Seventy two students were chosen and randomly divided into two experimental and control groups. The results of the 15 sessions of implementing the experiment showed that strategy instruction improved students' study skills and enabled them to promote their reading comprehension (Lee, 2007). Furthermore, Davis (2010) based on a meta-analysis of comprehension strategy instruction for upper elementary and middle school students in America, suggested that instruction on the use of reading comprehension strategies has a positive effect on students' achievements in grades 4-8.

\subsection{Cognitive and metacognitive reading strategies}

O' Malley and Chamot (1990) have conducted influential research on the effectiveness of learning strategies within an overall model of L2 learning based on cognitive psychology. They classified learning strategies into three fundamental categories of cognitive strategies, metacognitive strategies, and social strategies which are used in second language learning. These three strategies are defined as some of the reading strategies that have been developed and utilized before, during, and after the reading process. Weinstein and Mayer (1986) suggested that cognitive strategies include a majority of actions that help govern behavior, emotion, motivation, communication, attention, and comprehension. Cognitive strategies help students develop the necessary skills to be self-regulated learners, to facilitate comprehension, to act directly on incoming information, and ultimately improve academic performance. On the basis of cognitive view, linguistic knowledge and the skills to put the knowledge for text- meaning construction into use are two main factors related to successful comprehension (Koda, 2005). Metacognitive strategies are used to monitor and regulate cognitive strategies.

Metacognitive strategies involve planning, monitoring, checking the outcomes of learning, and regulating activities that focus on both the product and the process of reading skill. Metacognitive strategies can be defined as a set of strategies which support readers' awareness of comprehension- and help in the selection of cognitive strategies as a function of text difficulty, situational constraints, and the reader's own cognitive abilities (Lories, Darddene, \& Yzerbyt, 1998). Current studies show that metacognitive strategy instruction enhances L2 reading when compared to non-strategic training. They take a concise look at different models and patterns of early strategy use along with the metacognitive awareness that occur with that particular strategy use. Metacognitive strategies define a framework before, while, and after reading. Tang and Moore (1992) compared training effectiveness in cognitive and metacognitive strategies for improving comprehension among college ESL learners. Both yield similar comprehension gains after instruction, but only the metacognitive training showed long-term in continuous progress. In another study, O' Malley and Chamot (1990) found that teachers who applied superior metacognitive strategy instruction produced students who made greater progress in metacognitive knowledge. The results of various studies demonstrate that instructional outcomes become different according to strategy types- but the point is that why and how instructional effectiveness still differs among various strategies remains unknown.

\subsection{Summarizing and presentation Strategies}

There is some sort of need to aware students of the significance of the strategies which are used during the teaching and learning process. In this vein, summarizing strategy regarded as a teachable learning strategy that enables students to comprehend passages and solve their problems. Weinstein and Mayer (1986, p.315-327) described learning strategies as "thoughts and behaviors that learners engaged during learning". McLeod, Heiko, and Lockwood (1998) have conducted a study to explore the most effective learning strategies which are used by the students. The results revealed that the students made effective use of 'higher order' learning strategies including questioning and summarizing strategies (McLeod, Heiko, \& Lockwood, 1998). Based on what occurs in most Iranian teaching situations, the strategy which is most commonly used by Iranian teachers and students is the summarizing strategy. Several studies have showed that the use of summarizing strategy is an effective tool in helping students' comprehension and retention of materials. Soleimani and Nabizadeh (2012) examined the effect of learner constructed, fill in the map concept map technique (CM), and summarizing Strategy on Iranian pre-university students' reading comprehension. The results showed that despite the efficacy of all three strategies the fill in the map version of $\mathrm{CM}$ was the most influencing one. Nevertheless summarizing strategy is used as a frequent way of considering the main points of a passage; it generally suggested that $\mathrm{CM}$ technique might be regarded as an alternative or even as an effective replacement of the summarizing strategy for reading comprehension skill. In another study Chang, Sung, and Chen (2002) investigated the effect of concept-mapping strategies (map correction, scaffold fading, and map generation) on students' text comprehension and summarization abilities. The findings revealed that the map correction method improved reading comprehension and summarization-and the scaffold-fading method facilitated summarization (Chang, Sung, \& Chen, 2002). On the other hand, using presentation strategy, especially in today's classrooms, can be a huge advantage in trial. It is important to realize delivering effective presentations is dependent upon not only how students transfer information but how successfully they influence the whole class. Orally presentation of the passages assists students in comprehending and recalling of the texts effectively and creates selfconfident learners. In a research which has been conducted in 1977 Smiley, Oakley, Worthen, Campione, and Brown examined a group of 36 7th grades skilled and less skilled readers. Based on the treatment procedure, they read one prose passage and listened to a second one. They were tested orally for comprehension and recall of the passage contents after considering it. Under both reading and listening conditions, skilled readers recalled a greater proportion of the stories and poor readers recalled less of the stories. Orally presentation of the reading texts was significantly correlated with performance following listening. The findings revealed that poor readers have a general 
comprehension problem and that listening and reading have similar comprehension processes (Smiley, Oakley, Worthen, Campione, \& Brown, 1977).

\subsection{Models of Teaching Reading}

In recent literature on reading, language theorists and reading specialists have elaborated significant recommendations in describing the approaches to teaching and learning reading. Since reading takes into account word recognition and comprehension, there is some doubt whether students use a bottom-up approach to reading comprehension, a topdown approach or an interactive approach. Bottom-up model, top-down model, and interactive model are regarded as the three main models of teaching reading skill. According to Eskey (2005) these models facilitate reading comprehension and assist readers to understand texts and solve their problems during reading. Getting information from the printed texts is bottom-up processing. Dechant (2013) stated that bottom-up approach involves understanding the constituents of a passage. According to Dechant printed texts, analyzing letters, determining and joining the letters words, organizing words into larger units such as phrases, clauses, and sentences-relating meaning into these sentences. A majority of researches argue that in order to comprehend a text based on the bottom-up model, each reader must recognize each word in a sentence to comprehend the whole-and give primary emphasis to words and sound cues. Thus the bottom-up approach has been described as text-driven.

Recognition of the limitations within the bottom-up model in describing the reading process led to the emergence of the top-down reading model (Grabe, 2009; Eskey, 2005). Hedge (2000) pointed out that the top-down processing has been used to describe using of prior knowledge, intelligence, and experience to understand the meaning of a text. According to him this kind of processing is used when readers interpret assumptions and draw inferences. This model suggests that processing of massages begins in the mind of the readers with meaning-driven processes. Thus the topdown approach has been described as concept-driven. The top-down strategy advocators argue that each reader can comprehend a sentence even though they do not realize each word and that the primary goal of reading is reading for meaning. Although bottom-up and top-down models might be useful in reflecting different processes in reading- but we need to know that these approaches are used to complete each other. Successful reading involves using and coordinating both approaches while reading.

In order to compensate the shortcomings of the top-down model, the interactive model was emerged. Hedge (2000) describes that a reader continually shifts from one process to another, adopting a top-down approach to guess the probable meaning, and then moving to the bottom-up approach to check that it is really what the writer says. This has become known as interactive reading. According to this model meaning comes from many sources, that the reader simultaneously uses all levels of processing. In a very recent study, Ahmadi and Pourhossein Gilakjani (2012) defined the interactive model as a combination of both bottom-up and top-down models and emphasize the interrelationship between a reader and the text. They reported that interactive model is commonly accepted as the most conclusive picture of the reading process for both L1 and L2 readers (Ahmadi \& Pourhossein Gilakjani, 2012). Interactive strategy advocators argue that readers process letters and words as they simultaneously form hypotheses about the meaning of written texts and provide the most probable explanation of reading.

\subsection{Summary of Literature Review}

A vast majority of studies has been conducted on the domain of reading skill and its various dimensions. The findings of these researches substantiated the central role of reading in educational process. Having reviewed the literature on the importance and effectiveness of reading skill, reading comprehension, reading strategies, reading strategy use, and reading strategy instruction the current study attempted to figure out the effect of two reading strategies-summarizing and presentation- on students' reading comprehension. The study was proposed to add the body of literatures which are written in this regard.

\section{Methodology}

\subsection{Subjects}

The subjects of the current study were all enrolled at English Language Center of Chabahar Maritime University located in Chabahar/Iran. A total of 61 male and female students took part in this study. Their ages ranged from 18 to 27. Since only intermediate students were required for the purpose of the study, a standard proficiency test was administered. The homogeneity of students' proficiency level was established via the administration of a TOEFL (the PBT) proficiency test. Then they were randomly divided into two intact groups before the initiation of the study: one experimental group with a total of 31 students and one control group with a total of 30 students. The study was carried out for three sessions each week in 45 minutes by the researcher. The researcher herself taught them English language using "Top Notch" series level 2.

\subsection{Instruments}

\subsubsection{Data Collection Tools}

To accomplish the intended tasks, different instruments were used for data collection in the present study. 
A demographic questionnaire was administered to elicit relevant information on the subjects' age, gender, their educational level, their first language, the number of years they have lived in an English-speaking country, and their major of study.

\subsubsection{Placement Test}

Prior to starting the treatment, a standardized TOEFL proficiency test which was chosen from Longman Preparation Course for the TOEFL Test (PBT) was applied for the purpose of choosing students with intermediate level. Their homogeneity was ensured based on their performance on the TOEFL test.

\subsubsection{Reading Comprehension Pretest}

To conduct the study, a reading comprehension test as pretest was administered to subjects of both groups to make sure that they were homogeneous EFL readers before the initiation of the treatment. The pretest involved a total of 50 multiple choice items on five passages. All passages that were used in the reading comprehension pretest were selected from Longman Preparation Course for the TOEFL Test by Deborah Philips.

\subsubsection{Teaching Passages}

As previously stated the Top Notch series was the main book but along with this book the reading passages that were used to teach and test in this study were selected from two famous reading comprehension books entitled Reading and Vocabulary Development 3 Causes and Effect by Ackert and Lee (2005) and Active Skills for Reading: Book 3 by Anderson (2013). The reasons for choosing the reading passages from these two books were that since only intermediate level students were required in this study and since these books designed for intermediate learners, books of these series were selected for the purpose of this study. These books help students become more confident, independent, and active readers. All the selected passages were at the intermediate level, i.e. at the same level of the students. Thirty similar passages from these two books were selected to practice in both control and experimental groups.

\subsubsection{Reading Comprehension Immediate Posttest}

Students were assigned with several reading comprehension passages and tasks during the course. Ten reading comprehension tests were used as an immediate posttest to ensure of students' reading comprehension achievements after each two week separate instruction of summarizing and presentation strategies. Each immediate posttest involved two passages with 10 multiple choice items.

\subsubsection{Reading Comprehension Posttest}

A reading comprehension test similar to pretest was utilized as a posttest. It was used to check the potential differences in reading performance of the subjects over time at the end of the treatment. The posttest contained five passages with the same readability level and with a total of 50 multiple choice items as pretest. These passages were the same as the passages chosen for the pretest.

\subsection{Procedure}

This is an experimental study which was conducted within five months. The subjects of the study were students with intermediate level which were selected by administering a standard TOEFL proficiency test. Prior to the study, in order to determine the reading comprehension ability of the subjects a reading comprehension test as pretest was administered to both groups. The time allotted to accomplish the test was 55 minutes. The administration procedure of the pretest was similar for both groups. Once the pretest was administered to both groups, a treatment procedure was assigned to experimental group. Two flexible reading strategies including summarizing and presentation ones were the selected strategies which were implemented in the experimental group. The researcher (the teacher) first modeled and fully explained the summarizing and presentation strategies to the experimental group until she was confident that each student learned how to use them properly. The teacher provided the accompanying activities so that students were motivated to use the target passages.

There are some important components regarding these two strategies. First, students focused on important points of the texts. Second, they shared insights regarding the parts of the passages that are most interesting to them. Third, students learned how to present the texts and become self-regulated and self-confident. Finally, students are given opportunities to ask questions about the texts and discuss them with their classmates and also with the teacher. At the beginning of each regular English class (three times a week, typically 45 minutes in duration) subjects used the target strategy before approaching the main book contents. In the case of presentation strategy, the reading passages were taught in the first session and then the target subjects were assigned to present that particular passage for the next session. There were some sorts of discussions among students before, during, and after the presentation of the passages. Finally, they did the relevant exercises individually, in pairs or in small groups. Then in the case of summarizing strategy, after explicit instruction of the strategy, the reading passages were taught in the first session and then students were asked to summarize the passages at home and summit their works to the teacher. In the next session based on the subjects' summaries and their questions and problems, the researcher prepared some comments and feedback and provided them orally to all the students. The subjects read, shared, and discussed the reading and then completed the related exercises individually, in pairs or in small groups. And the recycle continued for each strategy until the end of the experiment. With the control group, the researcher followed the ordinary approaches of teaching reading comprehension. The control group class began with previewing the topic, focusing on main points of the passage, and finding new vocabularies. The students read the passages silently. Then the teacher taught the 
passage using the other ordinary strategies and approaches including skimming, scanning, and inferencing. -Finally, they completed the exercises individually, in pairs or in small groups.

Each of these two strategies was separately worked for two weeks, three sessions in each week in 45 minutes, and then at the end of each two week instruction an immediate posttest was administered to both groups according to the strategy worked. Five immediate posttests were carried out for each strategy within twenty weeks of instruction. Posttest data collection was conducted to both groups at the end of the twenty-week instruction, i.e., after the completion of the experiment.

\subsection{Data Analysis}

Statistical procedures used to analyze all the data in this study included mean scores, Paired sample t-test, and Independent sample t-test. They were used to process the data gained from each of the research instruments. The $21^{\text {st }}$ version of SPSS software was used for statistical analysis of the data collected from all of the research steps.

\section{Results}

In order to fulfill the purpose of the study, three tests were administered to the subjects: TOEFL proficiency test, reading comprehension test, and immediate posttest. Statistical procedures used to analyze all of the data included mean scores, Paired sample t-test, Independent sample t-test. SPSS version $21^{\text {st }}$ was used for statistical analysis. To achieve a general understanding of the differences between the two groups, mean scores were used before performing the main statistical test to answer the research questions. The groups were compared by the use of mean differences.

Table 1. Results of independent t-test for pretest in both groups

\begin{tabular}{|c|c|c|c|c|c|c|c|c|c|c|}
\hline \multicolumn{2}{|r|}{ Group } & Mean & $\mathrm{N}$ & $\begin{array}{c}\text { Std. } \\
\text { Deviation }\end{array}$ & $\begin{array}{l}\text { Std. } \\
\text { Error } \\
\text { Mean }\end{array}$ & \multicolumn{2}{|c|}{$\begin{array}{l}\text { Levene's Test } \\
\text { for Equality of } \\
\text { Variances }\end{array}$} & \multicolumn{3}{|c|}{$\begin{array}{l}\text { t-test for Equality of } \\
\text { Means }\end{array}$} \\
\hline pre & Control & 25.47 & 30 & 9.349 & 1.679 & $\mathrm{~F}$ & Sig & $\mathrm{t}$ & $\mathrm{df}$ & $\begin{array}{l}\text { Sig.(2- } \\
\text { tailed) }\end{array}$ \\
\hline & Experimental & 26.84 & 31 & 9.001 & 1.643 & .899 & .434 & -.403 & 82 & 988 \\
\hline
\end{tabular}

Regarding the statistics of Table 1 the mean of control group is 25.47 and experimental group is 26.84 . As it can be seen, level of significance is $0.98>0.05$. Since the level of significance is bigger than 0.05 , there is no significant difference between the groups in pretest. Therefore, it can be claimed that any measurable changes in the posttest is unlikely to be the effect of preexisting differences between two groups and can be attributed to the different treatments that these groups encountered.

Table 2. Results of independent t-test for posttest in both groups

\begin{tabular}{lcccccccccc}
\hline & Group & Mean & $\mathrm{N}$ & $\begin{array}{c}\text { Std. } \\
\text { Deviation }\end{array}$ & $\begin{array}{c}\text { Std. } \\
\text { Error } \\
\text { Mean }\end{array}$ & $\begin{array}{c}\text { Levene's Test } \\
\text { for Equality of } \\
\text { Variances }\end{array}$ & \multicolumn{2}{c}{$\begin{array}{c}\text { t-test for Equality of } \\
\text { Means }\end{array}$} & \\
\hline post & Control & 29.60 & 30 & 8.989 & 1.641 & F & Sig & t & df & $\begin{array}{c}\text { Sig.(2- } \\
\text { tailed) }\end{array}$ \\
\cline { 2 - 12 } & Experimental & 31 & 31 & 9.110 & 1.636 & .242 & .735 & -2.803 & 82 & .019 \\
\hline
\end{tabular}

To compare posttests in both groups independent t-test was used. As can be seen in table 2, mean of control group is 29.60 and experimental group is 31.52 . The level of significance found to be .019 . As the level of significance is smaller than $0.05,0.019<0.05$, it can therefore be concluded that there is a significant difference between experimental and control groups in the posttest. It means that experimental group significantly outperformed the control group in the post test.

Table 3. Results of the paired t-test for comparing pre and posttest of the control group 


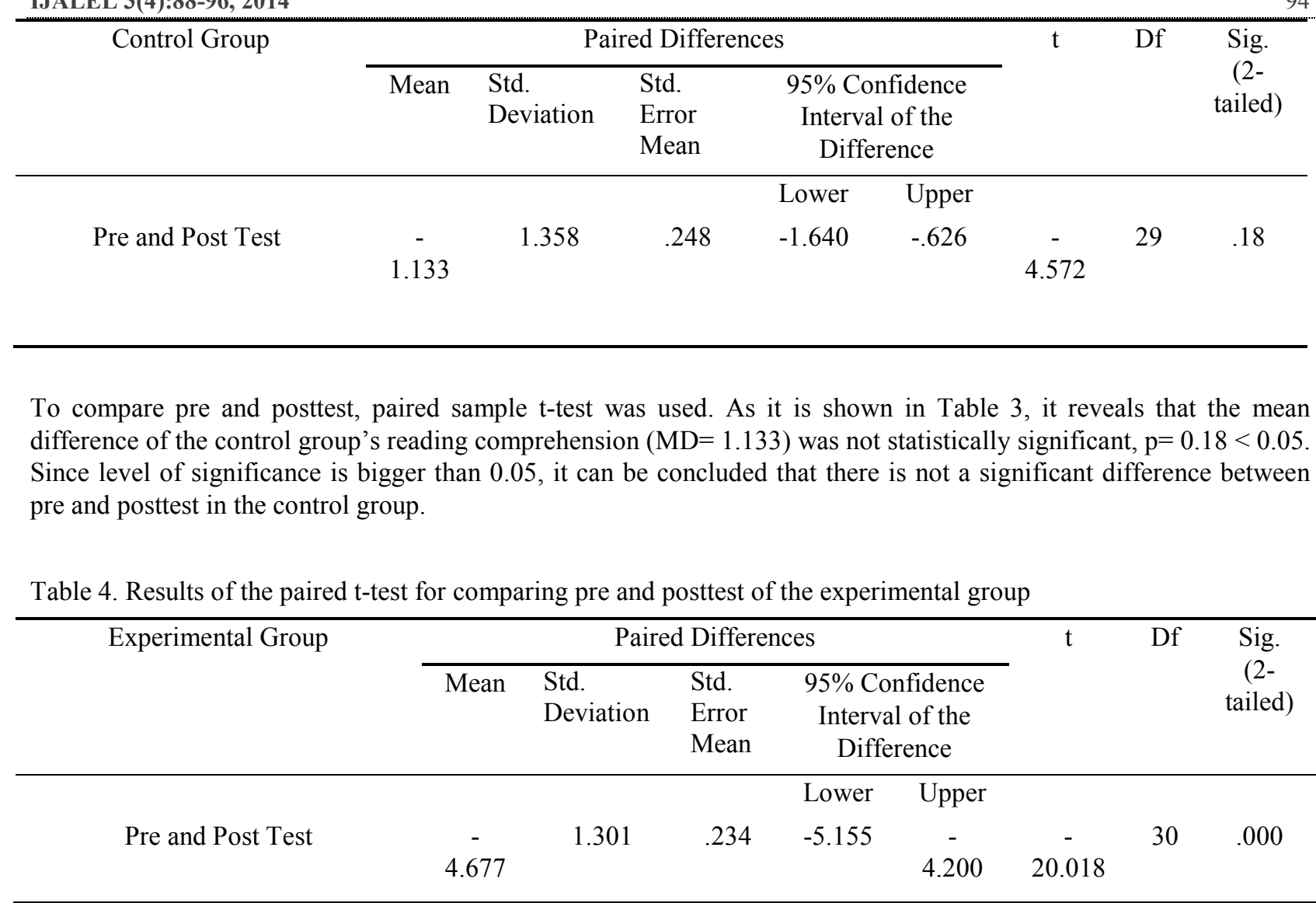

In order to compare pre and posttest of the experimental group, paired sample t-test was used. The statistical results of Table 4 revealed that mean difference of the experimental group's reading comprehension $(\mathrm{MD}=4.677)$ was statistically significant, $p=0.00<0.05$. Since level of significance is smaller than 0.05 , it can be concluded that the experimental group improved its reading comprehension in immediate posttests in comparison with reading pre-test, reading achievements of the experimental group can be attributed to the treatment. Posttest is significantly higher than pretest.

The results of the Independent sample t-test showed that presentation strategy was significantly more effective on students' reading comprehension. Delayed posttest was administered to investigate the effect of these reading strategies on students' reading comprehension over time.

\section{Discussion and Conclusion}

The findings of the current study are discussed in the following manners. The rationale for the present study was to provide the best reading experience for EFL students. The findings of various studies suggest that reading strategies provides teachable solutions for improving students' poor comprehension. As a result the primary purpose of the current study was proposed to determine the effect of summarizing and presentation strategies on EFL learners' reading comprehension. These techniques give students the opportunities to plan, monitor, and evaluate their reading performances. Thus as it was demonstrated in the data- students' general reading comprehension ability was improved by applying these two strategies. The results of this study are supported by both theoretical and empirical findings from previous research studies. The observed differences in the students' reading comprehension approve the findings of previous studies in both L1 and L2 reading-which have been demonstrated that reading strategy instruction improves reading comprehension and performance. The findings also confirm that summarizing and presentation strategies help students become engaged with the text by maximizing their cognitive and metacognitive monitoring skills.

By referring to statistical findings of this study, it can therefore be concluded that summarizing and presentation strategies lead to the improvement of students' reading comprehension ability. On the basis of what Krashen in 1982 argued, EFL learners' metalinguistic knowledge and conscious control over their performance result in improvements in their immediate posttest. In order to comprehend the texts, the students transacted with reading passages using these two particular strategies which were both cognitively and metacognitively manageable. The researcher tried to evaluate students' reading comprehension by measuring the students' ability to orally present and summarize the passages. Moreover, based on daily observations throughout the twenty weeks of instruction and the quantitative results of this study, it is suggested that these strategies gave students the opportunity to pause, read, synthesize, process information, comprehend, review the texts, and formulate questions regarding the topic of the study. These strategies are considered important but neglected practices in most language teaching and learning contexts.

Recent studies revealed that reading strategies are effective instruments for enhancing students' comprehension ability. Providing opportunities to practice reading strategies has a positive role on EFL learners' language 
performance and assist them become self-regulate language learners. Therefore, this study calls for a greater focus on teaching various reading strategies to EFL students to enhance their comprehension awareness. The study concludes with recommendations for training EFL students and teachers on using different comprehension strategies, especially those that have proven to be effective in promoting reading comprehension such as summarizing and presentation strategies.

This study also has several important teaching and pedagogical implications. First, EFL teachers should be encouraged to provide opportunities to use comprehension strategies such as summarizing and presentation which may contribute to better improvement of EFL students' reading comprehension achievements. This is because the general results of this study indicated that intermediate EFL students reacted positively towards the use of summarizing and presentation strategies and participated actively in the classroom process. Second, students should also have opportunities to discuss their understanding with their classmates via different techniques. This discussion helps raise students' comprehension awareness, determine their level of comprehension, self-correct their mistakes, and evaluate their comprehension. Thus the use of comprehension strategies plays a significant role in comprehending different varieties of texts.

The results of the study also confirmed the conclusions of reading comprehension analysis on language learning techniques and strategies which state this fact that application of particular strategies may attribute to the enhancement of students' reading comprehension. In sum, this study provides teachers with sufficient information on summarizing and presentation strategies utilized by Iranian intermediate EFL learners. Iranian English language practitioners should be aware of the necessity of implementing reading strategies including summarizing and presentation strategies in their regular classes to enhance students' comprehension abilities and skills. The findings of the current study allow teachers to get a general understanding of the application of these two strategies and to create opportunities for students to use summarizing and presentation strategies. Nevertheless, more research is still needed to be done on the effect of various reading strategies on students' reading achievements.

\section{References}

Ahmadi, M. R., \& Pourhossein Gilakjani, A. (2012). Reciprocal teaching strategies and their impacts on English reading comprehension. Theory and Practice in Language Studies , 2 (10), 2053-2060.

Alfassi, M. (2004). Reading to learn: Effects of combined strategy instruction on high school students. The Journal of Educational Research, 97 (4), 171-185.

Bossers, J. (1992). Reading in two languages: A study of reading comprehension in Dutch as a second language and in Turkish as a first language. Vrije Universiteit te Amsterdam .

Carrell, P. L. (1991). Second language reading: Reading ability or language proficiency? Applied Linguistics , 12 (2), 159-179.

Chang, K.-E., Sung, Y. T., \& Chen, I. D. (2002). The effect of concept mapping to enhance text comprehension and summarization. The Journal of Experimental Education , 71 (1), 5-23.

Davis, D. S. (2010). A meta-analysis of comprehension strategy instruction for upper elementary and middle school students(Unpublished doctoral dissertation, Vanderbilt University).

Dechant, E. (2013). Understanding and teaching reading: An interactive model. Routledge.

Duffy, G. G. (1993). Rethinking strategy instruction: Four teachers development and their low achievers understandings. The Elementary School Journal , 93 (3), 231-247.

Eskey, F. (2005). Tech talk:Better English through reading in science and technology. University of Michigan Press.

Grabe, W. (2009). Reading in a second language: Moving from theory to practice. Ernst Klett Sprachen .

Grabe, w., \& Stoller, F. L. (2002). Teaching and researching reading (2nd ed.). Routledge.

Hedge, T. (2000). Teaching and learning in the language classroom. Oxford: Oxford University Press.

Houtveen, A., \& Van de Grift, J. (2007). Effects of metacognitive strategy instruction and instruction time on reading comprehension. School Effectiveness and School Improvement: An International Journal of Research, Policy and Practice , 18 (2), 173-190.

Koda, K. (2005). Insights into second language reading: A cross-linguistic approach. Cambridge: Cambridge University Press.

Krashen, S. D. (1982). Principles and practice in second language acquisition. Oxford: Pergamon Press Inc.

Lee, S. K. (2007). Effects of textual enhancement and topic familiarity on Korean EFL students' reading comprehension and learning of passive form. Language Learning Research Club: A Journal of Research in Language Studies , 57 (1), 87-118.

Lems, K., Miller, L. D., \& Soro, T. M. (2010). Teaching reading to English language learners: Insights from applied linguistics. New York: The Guilford Press.

Lories, G., Darddene, B., \& Yzerbyt, V. Y. (1998). From social cognition to metacognition. Metacognition: Cognitive and Social Dimensios , 1-15. 
Marzano, R. J., Pickering, d. J., \& Pollock, J. E. (2001). Classroom instruction that works: Research-based strategies for increasing students achievement. New York: McREL.

McLeod, R. J., Heiko, D., \& Lockwood, P. (1998). A study of learning strategies used by students with the Oz Soils interactive multimedia program. Computer: Research and Graduate School of Education , 24 (3), 120-135.

Nambiar, R. (2009). Cross linguistic transfer between L1 and L2 Texts: Learning strategies used by bilingual Malay tertiary learners. European Journal of Social Science , 7 (3), 114-125.

Nunan, D. (1999). Second language teaching and learning. Boston: Heinle \& Heinle Pub.

O'Malley, M. J., \& Chamot, A. U. (1990). Learning strategies in second language acquisition. Cambridge: Cambridge University Press.

Salataci, R., \& Akyel, A. (2002). Possible effects of strategy instruction on L1 and L2 reading. Reading in a Foreign Language , 14 (1), 1-17.

Smiley, S. S., Oakley, D. D., Worthen, D., Campione, J. C., \& Brown, A. L. (1977). Recall of thematically relevant material by adolescent good and poor readers as a function of written versus oral presentation. Journal of Educational Psychology, 69 (4), 381-387.

Soleimani, H., \& Nabizadeh, F. (2012). The effect of learner constructed, fill in the map concept map technique,and summarising strategy on Iranian pre- university students' reading comprehension. Canadian Center of Science and Education , 5 (9).

Tang, H. N., \& Moore, D. W. (1992). Effects of cognitive and metacognitive pre-reading activities on the reading comprehension of ESL learners. Educational Psychology, 12 (3 and 4), 315-331.

Weinstein, C. E., \& Mayer, D. K. (1986). The teaching of learning strategies: The handbook of research on teaching. New York: MacMillan.

wright, M., \& brown, P. (2006). Reading in a modern foreign language: Exploring the potential benefits of reading strategy instruction. Language Learning Journal , 33 (1), 22-33. 